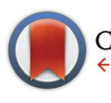

CrossMark

Cite this: Dalton Trans., 2016, 45 2647

Received 5th October 2015, Accepted 16th December 2015 DOI: $10.1039 / \mathrm{c} 5 \mathrm{dt} 03881 \mathrm{~b}$ www.rsc.org/dalton

\section{Heterocyclic dithiocarbamato-iron(III) complexes: single-source precursors for aerosol-assisted chemical vapour deposition (AACVD) of iron sulfide thin films $\uparrow$}

\author{
Sixberth Mlowe, ${ }^{a}$ David J. Lewis, ${ }^{b}$ Mohammad Azad Malik, a,b James Raftery, ${ }^{\text {b }}$ \\ Egid B. Mubofu, ${ }^{c}$ Paul O'Brien ${ }^{b}$ and Neerish Revaprasadu*a
}

\begin{abstract}
Tris-( piperidinedithiocarbamato)iron(III) (1) and tris-(tetrahydroquinolinedithiocarbamato)iron(III) (2) complexes have been synthesized and their single-crystal X-ray structures were determined. Thermogravimetric analysis (TGA) of the complexes showed decomposition to iron sulfide. Both complexes were then used as single-source precursors for the deposition of iron sulfide thin films by aerosol-assisted chemical vapour deposition (AACVD). Energy-dispersive X-ray (EDX) spectroscopy confirmed the formation of iron sulfide films. The addition of tert-butyl thiol almost doubled the sulfur content in the deposited films. Scanning electron microscopy (SEM) images of the iron sulfide films from both complexes showed flakes/leaves/sheets, spherical granules and nanofibres. The sizes and shapes of these crystallites depended on the nature of the precursor, temperature, solvent and the amount of tert-butyl thiol used. The observed optical properties are dependent upon the variation of reaction parameters such as temperature and solvent. Powder X-ray diffraction ( $p$-XRD) studies revealed that pyrrhotite, hexagonal $\left(\mathrm{Fe}_{0.975} \mathrm{~S}\right)$, marcasite and smythite $\left(\mathrm{Fe}_{3} \mathrm{~S}_{4}\right)$ phases were differently deposited.
\end{abstract}

\section{Introduction}

Iron sulfide, the most abundant transition metal chalcogenide in the earth's crust, is potentially significant for several applications including biomedical and catalytic processes, ${ }^{1,2}$ hydrogen generation, ${ }^{3,4}$ environmental remediation, ${ }^{5}$ batteries and solar cells. ${ }^{6-8}$ Potentially, it has a number of advantages over many other materials including low toxicity and cost, vacancydependent crystalline structures which could be useful in bandgap tuning across quantum confinement regimes, as well as interesting magnetic and electric properties. ${ }^{9}$ It exists in various forms including pyrite (cubic-Fes ${ }_{2}$ ), marcasite (orthorhombic- $\mathrm{FeS}_{2}$ ), pyrrhotite $\left(\mathrm{Fe}_{1-X} \mathrm{~S}\right)$, greigite (cubic spinel$\mathrm{Fe}_{3} \mathrm{~S}_{4}$ ), smythite $\left(\mathrm{Fe}_{3} \mathrm{~S}_{4}\right)$, troilite-2H (FeS) and mackinawite $\left(\mathrm{Fe}_{1+X} \mathrm{~S}\right) .{ }^{10,11}$ The phase diagram of iron-sulfur compounds is complex, and a small variation in stoichiometry often leads to

\footnotetext{
${ }^{a}$ Department of Chemistry, University of Zululand, Private Bag X1001,

KwaDlangezwa, 3886, South Africa.E-mail: RevaprasaduN@unizulu.ac.za

${ }^{b}$ Schools of Chemistry and Materials, The University of Manchester, Oxford Road, Manchester, M13 9PL, UK

${ }^{c}$ Department of Chemistry, University of Dar es Salaam, P.O. Box 35061,

Dar es Salaam, Tanzania

$\dagger$ Electronic supplementary information (ESI) available. CCDC 984433 and 1008838. For ESI and crystallographic data in CIF or other electronic format see DOI: $10.1039 / \mathrm{c} 5 \mathrm{dt} 03881 \mathrm{~b}$
}

drastic changes in the structural, magnetic, electronic and physical properties of the chalcogenide formed. ${ }^{9,12}$

Iron sulfide compounds exhibit a wide range of properties, from the semiconducting $\mathrm{FeS}_{2}$ to ferromagnetic $\mathrm{Fe}_{3} \mathrm{~S}_{4} \cdot{ }^{13}$ In contrast to the properties of their bulk counterparts, iron sulfide thin films and nanoparticles can exist in magnetic structures with enhanced surface contributions. Amongst the iron sulfide phases, cubic-FeS ${ }_{2}$ (pyrite) has attracted most interest, in particular in the development of thin-film solar cells and solid-state batteries, owing to its properties which include strong light absorption $\left(\sim 5 \times 10^{5} \mathrm{~cm}^{-1}\right)$ and a direct band gap of $0.95 \mathrm{eV} .^{14-17}$

Several studies on the deposition of iron sulfide thin films using single source precursors have been reported. ${ }^{18-20}$ Aerosolassisted chemical vapour deposition (AACVD) is a versatile route for the deposition of iron sulfide thin films. The morphology, particle size and crystal-structure of the films deposited by this route can be closely controlled by the choice of a suitable solvent, deposition temperature and the nature of the precursor. We have been using single source precursors for metal chalcogenide thin films or nanoparticles and recently used complexes such as dithiocarbamates, ${ }^{21-24}$ thiosemicarbazone ${ }^{25}$ and thiobiurets $^{26}$ for the preparation of Fe-S thin films by AACVD.

Herein we report the synthesis and X-ray crystal structures of new iron(III) dithiocarbamate complexes, tris-(piperidine- 
dithiocarbamato)iron(III) (1) and tris-(tetrahydroquinolinedithiocarbamato)iron(III) (2). These complexes have been used as single-source precursors for the deposition of iron sulfide thin films by AACVD. Powder X-ray diffraction, scanning electron microscopy and optical measurements reveal that the structural and electronic properties of the as-prepared nanostructured iron sulfide films are strongly dependent on sample preparation conditions such as temperature and solvent effects. The effect of temperature and solvent also played an important role in controlling the surface morphology and phase chemistry of the deposited films. Structural and morphological transformations in the deposited films were also observed as a result of the change in the chemical structure of the starting materials, allowing the fabrication of rare phases of iron sulfide that have not been accessed before by AACVD. The decomposition mechanism of complex (1) is also proposed, based upon thermal analysis, gas chromatography mass spectroscopy (GC MS) and powder X-ray diffraction studies.

\section{Experimental}

\section{Materials}

Piperidine 99\%, tert-butylthiol, toluene, hexane, chloroform and carbon disulfide $99.5 \%$ were purchased from SigmaAldrich. Iron(III) chloride 99\% and tetrahydroisoquinoline 96\% were purchased from Merck Chemicals. Chemicals were used without further purification.

\section{Characterization of precursors}

The elemental analysis of C, H, N, S and Fe was carried out on a Carlo Erba EA 1108 elemental analyser which had been calibrated with standard reference materials. Fourier transform infrared spectra were recorded in the range $200-4000 \mathrm{~cm}^{-1}$ using a Bruker FT-IR Tensor 27 spectrophotometer. Thermogravimetric analysis was carried out at $10{ }^{\circ} \mathrm{C} \mathrm{min}^{-1}$ heating rate using a Perkin-Elmer Pyris 6 TGA from 30 to $700{ }^{\circ} \mathrm{C}$ in a closed perforated aluminium pan under $\mathrm{N}_{2}$ gas. Spray gas chromatography mass spectroscopy (GC-MS) analyses were performed on a Kratos concept 1-S instrument.

Single crystal X-ray diffraction data for the compounds were collected using graphite monochromated $\mathrm{Cu}-\mathrm{K}_{\alpha}$ radiation $(\lambda=$ $1.54178 \AA$ ) on a Bruker APEX diffractometer. The structure was solved by direct methods and refined by full-matrix least squares on $F^{2}$. All non-H-atoms were refined anisotropically. Hydrogen atoms were included in calculated positions, assigned isotropic thermal parameters and allowed to ride on their parent carbon atoms. All calculations were carried out using the SHELXTL software package. ${ }^{27}$ The crystallographic refinement parameters are detailed as follows:

$\mathrm{X}$-ray experimental and structural refinement data for $\mathrm{C}_{18} \mathrm{H}_{30} \mathrm{FeN}_{3} \mathrm{~S}_{6}$ (1) (Fig. 2). $\mathrm{C}_{18} \mathrm{H}_{30} \mathrm{FeN}_{3} \mathrm{~S}_{6}, M=$ 536.66, monoclinic, space group $C 2 / c, a=13.0387(9), b=11.8818(9), c=$ 15.9260(15) $\AA, \alpha\left(^{\circ}\right)=90, \beta\left(^{\circ}\right)=101.292(6), \gamma\left({ }^{\circ}\right)=90$, volume $=$ 2419.5(3) $\AA^{3}, Z=4, D=1.473 \mathrm{Mg} \mathrm{m}^{-3}, T=100(2) \mathrm{K}$, reflections collected $=8309 / 2300$, unique reflections $=[R(\mathrm{int})=0.0695]$, final $R$ indices $[I>2 \sigma(I)] R_{1}=0.0541, \mathrm{w} R_{2}=0.1176, R$ indices (all data) $R_{1}=0.0707, \mathrm{w} R_{2}=0.1336$, largest diff. peak and

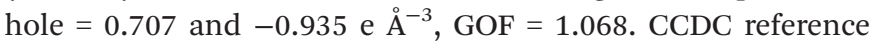
number 984433.

$\mathrm{X}$-ray experimental and structural refinement data for $\mathrm{C}_{30} \mathrm{H}_{30} \mathrm{Fe}_{1} \mathrm{~N}_{3} \mathrm{~S}_{6}$ (2) (Fig. 3). $\mathrm{C}_{30} \mathrm{H}_{30} \mathrm{Fe}_{1} \mathrm{~N}_{3} \mathrm{~S}_{6}, M=680.78$, orthorhombic, space group Pca2(1), $a=21.9551(8), b=18.8423(6)$, $c=14.7741(4) \AA, \alpha\left(^{\circ}\right)=90, \beta\left(^{\circ}\right)=90, \gamma\left(^{\circ}\right)=90$, volume $=$ $6111.8(3) \AA^{3}, Z=4, D=1.480 \mathrm{Mg} \mathrm{m}^{-3}, T=100(2) \mathrm{K}$, reflections collected $=24173 / 8695$, unique reflections $=[R($ int $)=0.0991]$, final $R$ indices $[I>2 \sigma(I)] R_{1}=0.0670, \mathrm{w} R_{2}=0.1576, R$ indices (all data) $R_{1}=0.1083, \mathrm{w} R_{2}=0.1784$, largest diff. peak and hole

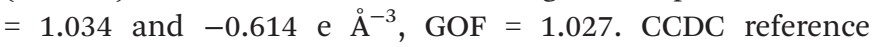
number 1008838 .

\section{Characterization of iron sulfide thin films}

Powder XRD diffraction studies were performed on a Bruker AXS D8 diffractometer using $\mathrm{Cu}-\mathrm{K} \alpha$ radiation $(\lambda=1.54178 \AA)$ at $40 \mathrm{kV}, 40 \mathrm{~mA}$, room temperature. The samples were mounted flat and scanned between 20 and $70^{\circ}$ in a step size of 0.05 with a count of 10 s. Scanning electron microscopy (SEM) was carried out using a Philips XL30 FEG SEM. Energy-dispersive X-ray (EDX) spectroscopy was performed using a DX4 detector. All samples were carbon coated using an Edwards coating system E306A prior to SEM analysis. Atomic force microscopy (AFM) analysis of the iron sulfide thin films was carried out using a Bruker Multimode 8 instrument operating in Peakforce QNM mode. A Perkin Elmer Lambda 1050 UV-Vis NIR spectrometer was used to carry out the optical absorbance measurements of the iron sulfide thin films in the wavelength range 200-3000 nm.

\section{Synthesis and characterization of iron(III) heterocyclic dithiocarbamate complexes}

Organic salts of sodium piperidine and/or tetrahydroquinolinedithiocarbamato ligands were prepared according to procedures reported in the literature ${ }^{28}$ and were then converted to the corresponding iron(III) complexes by salt metathesis. A brief description of the synthesis of complexes is given below.

To an aqueous solution of $\mathrm{FeCl}_{3}(0.82 \mathrm{~g}, 5.0 \mathrm{mmol})(25 \mathrm{~mL})$ was added dropwise an aqueous solution of the ligand, $\mathrm{NaC}_{10} \mathrm{NS}_{2} \mathrm{H}_{10}(3.482 \mathrm{~g}, 15.0 \mathrm{mmol})$, dissolved in a minimal amount of water, with vigorous stirring. The reaction mixture was stirred for a further $1 \mathrm{~h}$ before being filtered. The blackcoloured solids were washed with deionized water and dried under vacuum overnight. The compound was found to be soluble in solvents such as chloroform and dichloromethane and solubility in toluene is enhanced at elevated temperatures. The complexes were recrystallized from chloroform and hexane $(1: 1)$ by the diffusion method, to obtain crystals of complex (1) $\mathrm{C}_{18} \mathrm{H}_{30} \mathrm{FeN}_{3} \mathrm{~S}_{6}$. Complex (2) $\mathrm{C}_{30} \mathrm{H}_{30} \mathrm{FeN}_{3} \mathrm{~S}_{6}$ was prepared in a similar manner.

Yield 79.7\%. Elemental analysis for $\mathrm{C}_{18} \mathrm{H}_{30} \mathrm{FeN}_{3} \mathrm{~S}_{6}$ : Calc: C, 40.28; H, 5.63; N, 7.83; S, 35.85; Fe, 10.41. Found: C, 40.32; H, 5.73; N, 7.94; S, 35.34; Fe, 9.55. IR $\left(\mathrm{cm}^{-1}\right): 1422(\mathrm{C}=\mathrm{N}), 965$ $(\mathrm{C}=\mathrm{S}), 365(\mathrm{Fe}-\mathrm{S})$. 
Table 1 Summary of iron sulfide thin films obtained from complexes (1) and (2) under different reaction conditions

\begin{tabular}{|c|c|c|c|}
\hline Precursor & Reaction conditions & Morphology & Phase \\
\hline \multirow[t]{2}{*}{ Complex (1) } & Toluene, $350-450^{\circ} \mathrm{C}, 2 \mathrm{~h}$ & Leaf, flake, sheet & Hexagonal $\left(\mathrm{Fe}_{0.975} \mathrm{~S}\right)$, marcasite $\left(\mathrm{FeS}_{2}\right)$ \\
\hline & Chloroform, $350-450^{\circ} \mathrm{C}, 30$ minutes & Fiber & Hexagonal $\left(\mathrm{Fe}_{0.975} \mathrm{~S}\right)$, smythite $\left(\mathrm{Fe}_{3} \mathrm{~S}_{4}\right)$ \\
\hline \multirow[t]{3}{*}{ Complex (2) } & Toluene, $350-450^{\circ} \mathrm{C}, 2 \mathrm{~h}$ & Leaf, flake, sheet & Pyrrhotite $\left(\mathrm{Fe}_{0.95} \mathrm{~S}_{1.05}\right)$, hexagonal $\left(\mathrm{Fe}_{0.975} \mathrm{~S}\right)$ \\
\hline & Chloroform, $350-450{ }^{\circ} \mathrm{C}, 30$ minutes & Fiber & Hexagonal $\left(\mathrm{Fe}_{0.975} \mathrm{~S}\right)$ \\
\hline & tert-Butyl thiol, $450^{\circ} \mathrm{C}, 2 \mathrm{~h}$ & Spherical and flake & Greigite $\left(\mathrm{Fe}_{3} \mathrm{~S}_{4}\right)$ \\
\hline
\end{tabular}

Yield 62.4\%. Elemental analysis for $\mathrm{C}_{30} \mathrm{H}_{30} \mathrm{FeN}_{3} \mathrm{~S}_{6}$ : Calc: C, 52.93; H, 4.54; N, 6.17; S, 28.26; Fe, 8.20. Found: C, 53.19; H, 4.99; N, 6.42; S, 27.76; Fe, 7.81. IR $\left(\mathrm{cm}^{-1}\right): 1440(\mathrm{C}=\mathrm{N}), 978$ $(\mathrm{C}=\mathrm{S}), 383(\mathrm{Fe}-\mathrm{S})$.

\section{Deposition of iron sulfide thin films by AACVD}

Iron sulfide thin films were deposited on glass substrates using AACVD and precursors (1) and (2); the AACVD assembly is similar to that described in the literature. ${ }^{21}$ The glass substrates were ultrasonically cleaned in distilled water and acetone and then finally stored in ethanol prior to use. In a typical deposition procedure, aerosols of the desired complex from its $46 \mathrm{mM}$ solution ( $8 \mathrm{~mL}$ ) (chloroform or toluene, as suitable solvents) are generated at room temperature using an ultrasonic humidifier operating at $50 \mathrm{~Hz}$ frequency. Argon was used as a carrier gas for the aerosols to be transported to the reactor chamber, at a flow rate of $160 \mathrm{~mL} \mathrm{~min}{ }^{-1}$. Deposition experiments were conducted for $30 \mathrm{~min}$ and 2 hours for chloroform and toluene solutions, respectively. Table 1 provides a summary of the results obtained from deposition of iron sulfide films using complexes (1) and (2).

\section{Results and discussion}

\section{Single source precursors}

The single crystal X-ray structure of tris-(piperidinedithiocarbamato)iron(III) (1) is shown in Fig. 1(a). The X-ray structure has an octahedral iron cation coordinated by six sulfur atoms from the three bidentate piperidinedithiocarbamato ligands. The bond distances of Fe-S range from 2.2920 to 2.3067 A. Structural refinement data are given in the Experimental section; selected bond angles and lengths are presented in the caption to Fig. 1(a).

The single crystal X-ray structure of tris-(tetrahydroisoquinolinedithiocarbamato)iron(III) (2) is shown in Fig. 1(b). The structure also shows a distorted octahedral environment with the Fe-S distances between 2.293 and $2.316 \AA$, longer than those of complex (1). The Fe-S bond lengths from both complexes (1) and (2) are closer to those observed in our previous work. ${ }^{29}$ The bite angles $75.20^{\circ}, 75.78^{\circ}$ and $75.86^{\circ}$ of $\mathrm{S} 1-\mathrm{Fe} 1-$ S2, S3-Fe1-S4 and S5-Fe1-S6, respectively, further reveal the distorted octahedral geometry on iron(III). Structural refinement data are given in the Experimental section; selected bond angles and lengths are presented in the caption to Fig. 1(b).

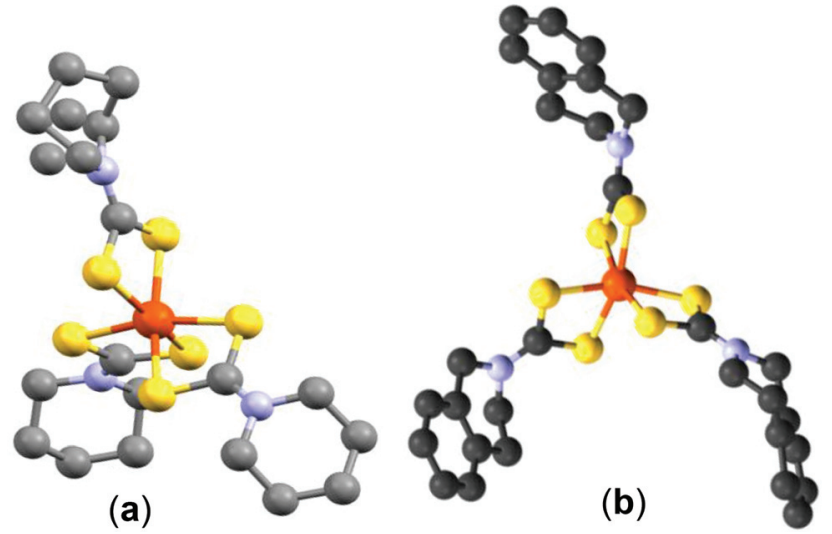

Fig. 1 (a) The $X$-ray single crystal structure of $\mathrm{C}_{18} \mathrm{H}_{30} \mathrm{FeN}_{3} \mathrm{~S}_{6}(\mathrm{CCDC}$ 984433) (red $=\mathrm{Fe}$, yellow $=\mathrm{S}$, blue $=\mathrm{N}$ and black $=\mathrm{C}$ ). Selected bond lengths $(\AA)$ and bond angles $\left({ }^{\circ}\right)$ : $\mathrm{Fe}(1)-\mathrm{S}(1) 2.2920$ (13), $\mathrm{Fe}(1)-\mathrm{S}(1) \# 1$ 2.2920 (13), Fe(1)-S(3) \#1 2.3003 (13), Fe(1)-S(3) 2.3003 (13), Fe(1)-S(2) 2.3067 (13), Fe(1)-S(2) \#1 2.3067 (13), S(1)-Fe(1)-S(1) \#1 99.40 (7), S(1)$\mathrm{Fe}(1)-\mathrm{S}(3)$ \#1 93.87 (4), S(1) \#1-Fe(1)-S(3) \#1 162.84 (5), S(1)-Fe(1)-S(3) 162.84 (5), S(1) \#1-Fe(1)-S(3) 93.88 (4), S(3) \#1-Fe(1)-S(3) 75.46 (6), $\mathrm{S}(1)-\mathrm{Fe}(1)-\mathrm{S}(2) 75.81$ (5), S(1) \#1-Fe(1)-S(2) 94.62 (5), S(3) \#1-Fe(1)-S(2) 99.17 (5), S(3)-Fe(1)-S(2) 92.41 (5), S(1)-Fe(1)-S(2) \#1 94.62 (5), S(1) \#1$\mathrm{Fe}(1)-\mathrm{S}(2)$ \#1 75.81 (5), S(3) \#1-Fe(1)-S(2) \#1 92.41 (5), S(3)-Fe(1)-S(2) \#1 99.17 (5), S(2)-Fe(1)-S(2) \#1 165.37 (8). (b) The X-ray single crystal structure of $\mathrm{C}_{30} \mathrm{H}_{30} \mathrm{FeN}_{3} \mathrm{~S}_{6}(\mathrm{CCDC} 1008838)$ (red $=\mathrm{Fe}$, yellow $=\mathrm{S}$, blue $=$ $\mathrm{N}$ and black $=\mathrm{C})$. Selected bond lengths $(\AA)$ and bond angles $\left({ }^{\circ}\right)$ : $\mathrm{Fe}(1)-$ $\mathrm{S}(6) 2.293$ (3), $\mathrm{Fe}(1)-\mathrm{S}(2) 2.299$ (3), $\mathrm{Fe}(1)-\mathrm{S}(3) 2.307$ (3), $\mathrm{Fe}(1)-\mathrm{S}(5)$ 2.308 (3), Fe(1)-S(4) 2.309 (3), Fe(1)-S(1) 2.316 (3), S(6)-Fe(1)-S(2) 95.56 (11), S(6)-Fe(1)-S(3) 163.17 (12), S(2)-Fe(1)-S(3) 96.38 (11), S(6)$\mathrm{Fe}(1)-\mathrm{S}(5) \quad 75.86 \quad(10), \quad \mathrm{S}(2)-\mathrm{Fe}(1)-\mathrm{S}(5) \quad 163.44 \quad$ (12), S(3)-Fe(1)-S(5) 95.21 (11), S(6)-Fe(1)-S(4) 91.27 (11), S(2)-Fe(1)-S(4) 95.70 (11), S(3)$\mathrm{Fe}(1)-\mathrm{S}(4) \quad 75.78 \quad(10), \quad \mathrm{S}(5)-\mathrm{Fe}(1)-\mathrm{S}(4) \quad 98.59 \quad(10), \quad \mathrm{S}(6)-\mathrm{Fe}(1)-\mathrm{S}(1)$ 99.53 (11), S(2)-Fe(1)-S(1) 75.20 (10), S(3)-Fe(1)-S(1) 94.97 (11), S(5)$\mathrm{Fe}(1)-\mathrm{S}(1) 92.06$ (10), S(4)-Fe(1)-S(1) 166.42 (12).

Thermogravimetric analysis (TGA) of complex (1) showed a two-step decomposition pattern with a rapid weight loss of $15.6 \%$ and $65.5 \%$ at $210{ }^{\circ} \mathrm{C}$ and $304{ }^{\circ} \mathrm{C}$, respectively (Fig. 2). The weight of the remaining residue is $15.7 \%$, which corresponds to FeS (calculated percentage 16.4\%). The thermogram of complex (2) shows an ill-defined three-step decomposition pattern with a weight loss of $28.0 \%, 44.3 \%$ and $7.1 \%$ at $207{ }^{\circ} \mathrm{C}$, $257{ }^{\circ} \mathrm{C}$ and $351{ }^{\circ} \mathrm{C}$, respectively; the final weight of $11.8 \%$ (calculated $12.9 \%$ ) is assumed to be a residue of the iron sulfide material, which is sulfur deficient (Fig. 2). The thermogram of complex (2) seems to continue changing on approaching $700{ }^{\circ} \mathrm{C}$, possibly due to residual carbonaceous species in the 


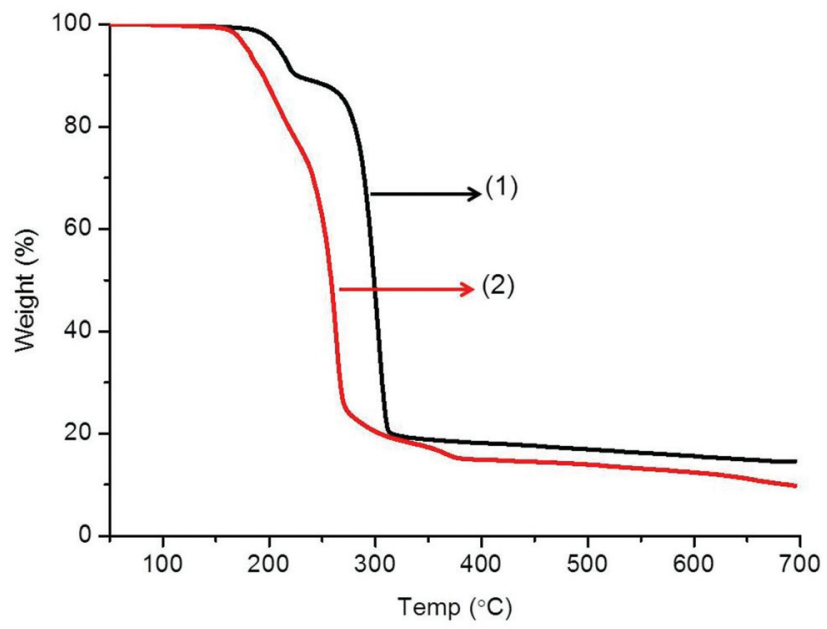

Fig. 2 Thermogravimetric analysis (TGA) of complexes (1) and (2) at a heating rate of $10{ }^{\circ} \mathrm{C} \mathrm{min}^{-1}$ under nitrogen with a flow rate of $10 \mathrm{~cm}^{3} \mathrm{~min}^{-1}$.

films, or sublimation of the iron sulfide product, perhaps leading to sulfur deficient phases. Another possibility is that oxide phases form; Fe is very oxophilic and the nitrogen in the TGA is probably not that dry or oxygen free.

The decomposition mechanism of complex (1) was investigated using thermogravimetric analysis (TGA), gas chromatography mass spectroscopy (GC/MS) and powder X-ray diffraction ( $\mathrm{p}$-XRD). Thermal studies show that the decomposition of the complex (1) proceeds through two major steps: (i) detachment of one of the three dithiocarbamate ligands in the six coordinated tris-(piperidinedithiocarbamato)iron(III) complex, thus forming an intermediate four coordinated complex, and lastly (ii) the final decomposition/elimination $\left(304{ }^{\circ} \mathrm{C}\right)$ of the four coordinated dithiocarbamato complex of iron to afford materials of either FeS or indefinite Fe-S composition (Fig. 3). The first weight loss of $15.6 \%$ is smaller than the weight of the anticipated release of only one piperidine dithiocarbamate ligand $(\sim 29 \%)$. Thus, the first step may involve partial decomposition, rearrangement of the complex and/or reduction to a Fe(II) complex. The GC mass spectrum of complex (1) also confirmed complete decomposition of the complex via two steps (ESI Fig. $1 \dagger$ ): (i) elimination of one piperidinyl dithiocarbamato ligand $(\mathrm{m} / \mathrm{z} 160)$, followed by (ii) complete removal of the remaining organic components $(\mathrm{m} / \mathrm{z} 290)$, thus affording FeS as the final product $(\mathrm{m} / \mathrm{z} 86)$.

A separate study which aimed at identifying the existence of temperature-dependent phase transformation in the iron sulfide materials was carried out. The progress of this experiment was monitored using powder X-ray diffractometry. Diffraction studies (ESI Fig. $2 \dagger$ ) were carried out at a heating rate of $2.5^{\circ} \mathrm{C} \mathrm{h}^{-1}$, where complex (1) was the starting material heated from $180{ }^{\circ} \mathrm{C}$ to $310{ }^{\circ} \mathrm{C}$ under $\mathrm{N}_{2}$ flow. A total of 27 diffraction patterns were collected. The hexagonal phase (card number 01-080-1032) of iron sulfide and mackinawite (card number 04-003-6935) became prominent with an increase in tempera-

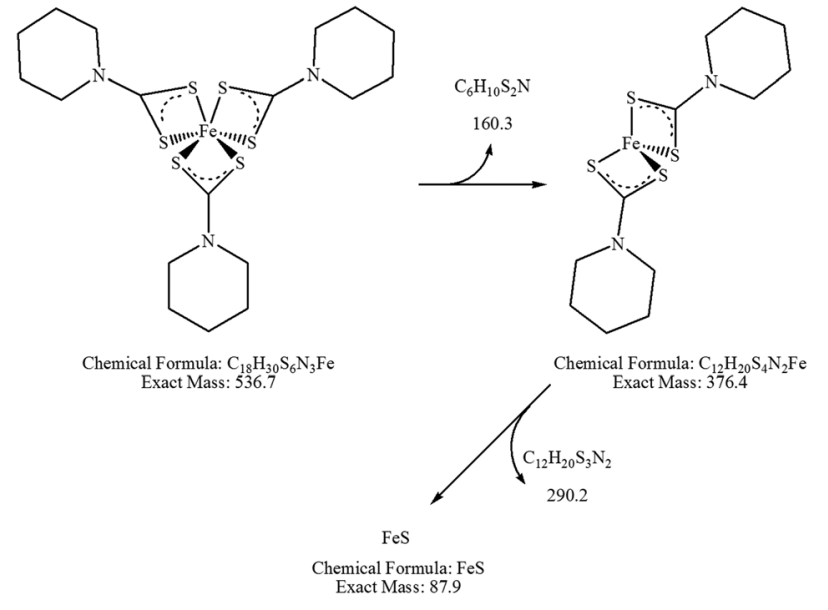

Fig. 3 Proposed decomposition mechanism of complex (1) $\mathrm{C}_{18} \mathrm{H}_{30} \mathrm{FeN}_{3} \mathrm{~S}_{6}$.

ture, with few peaks unassigned. The observed temperatures for the occurrence of Fe-S phases are lower than those established from phase diagrams, probably due to the prolonged time of the diffraction analysis and heating.

\section{Deposition of iron sulfide thin films using toluene solution}

Thin films of iron sulfide were deposited on glass substrates by AACVD at three different temperatures: 350,400 and $450{ }^{\circ} \mathrm{C}$ using either chloroform or toluene (sonicated at $70{ }^{\circ} \mathrm{C}$ ) as solvents. The films produced were characterized by scanning electron microscopy (SEM), energy dispersive X-ray (EDX) spectroscopy, powder X-ray diffraction (p-XRD), optical absorbance spectroscopy and atomic force microscopy (AFM).

The SEM images of iron sulfide films in Fig. 4 deposited using complex (1) in toluene solvent show the growth of sheetlike structures at $350{ }^{\circ} \mathrm{C}$ and nano-leaf/flake like crystallites at $400{ }^{\circ} \mathrm{C}$ and $450{ }^{\circ} \mathrm{C}$. The film size increased with an increase in deposition temperature; an increase in film size of 0.6-1.0 $\mu \mathrm{m}$ was observed when the temperature was increased to $400{ }^{\circ} \mathrm{C}$ and $450{ }^{\circ} \mathrm{C}$. Some microstructures on the surfaces were also observed. The morphology obtained from this study is reasonably similar to that of our recently reported iron sulfide thin films deposited using iron thiobiuret and diethyldithiocarbamate complexes. ${ }^{21,27}$ EDX spectroscopy on five different areas of the films showed that the compositions are slightly sulfur deficient, a trend that increased at an elevated temperature (Table 2).

A similar trend was observed when complex (2) was used as the single source precursor to deposit a pyrrhotite film (Fig. 5a and b). The images illustrate the formation of typical nanosheet-like structures. A slight morphological transformation is observed, as a result of the change in the chemical structure of the starting materials.

The back-scattered electron (BSE) SEM image (which provide $Z$ contrast) of iron sulfide films shows small particles with bright contrast embedded into flakes of darker contrast. 

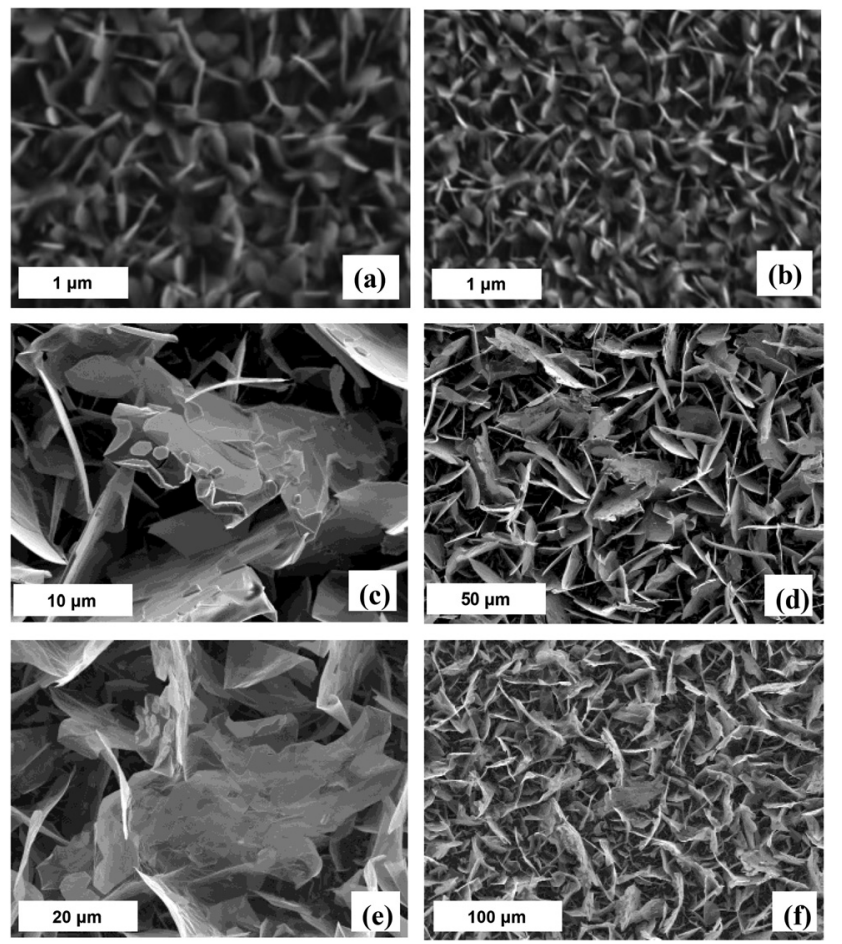

Fig. 4 Representative secondary electron SEM images of the iron sulfide thin films deposited at (a and b) $350{ }^{\circ} \mathrm{C}, 400{ }^{\circ} \mathrm{C}$ (c and d) and (e and f) $450^{\circ} \mathrm{C}$ using complex (1).

Table 2 Elemental composition found by EDX spectroscopy of Fe and $\mathrm{S}$ in the thin films deposited using complex (1)

\begin{tabular}{llll}
\hline Temp $\left({ }^{\circ} \mathrm{C}\right)$ & Fe $(\%)$ & $\mathrm{S}(\%)$ & Ratio $(\mathrm{Fe}: \mathrm{S})$ \\
\hline 350 & 57.3 & 42.7 & $\mathrm{Fe}_{(1+x)} \mathrm{S}, x=0.3$ \\
400 & 60.8 & 39.2 & $\mathrm{Fe}_{(1+x)} \mathrm{S}, x=0.5$ \\
450 & 66.3 & 33.7 & $\mathrm{Fe}_{2} \mathrm{~S}$
\end{tabular}
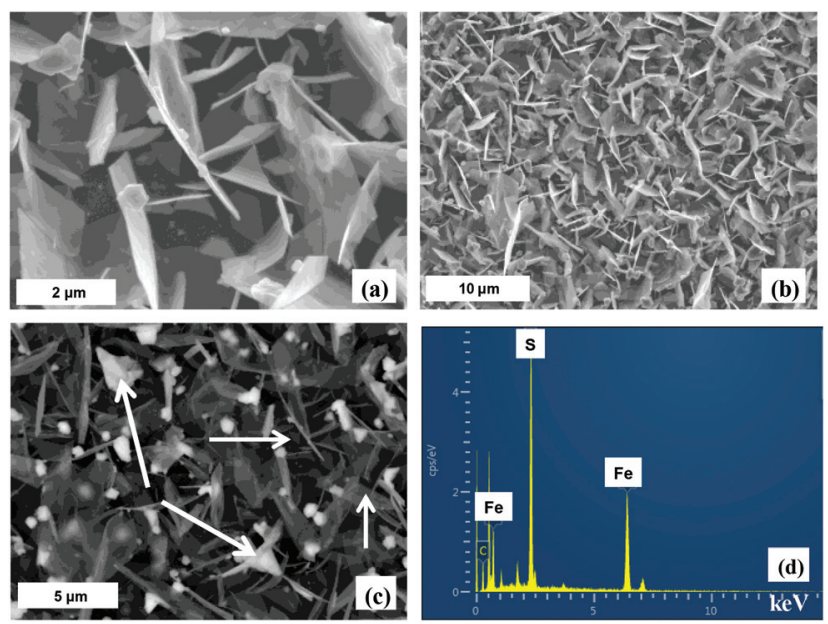

Fig. 5 Representative secondary electron SEM images of the iron sulfide thin films deposited at ( $a$ and b) $450^{\circ} \mathrm{C}$ and a backscattered electron SEM image (c) and a representative EDX spectrum (d) when complex (2) was used.
Point scanning EDX spectroscopy revealed that the white spots (chunks) were S-rich (Fe 53.7\% and S 46.3\%), while the opposite is observed for the black spots (flakes) which are Fe-rich (Fe 66.9\% and S 33.1\%) (Fig. 5c). This phenomenon validates that $\mathrm{Fe}$ and $\mathrm{S}$ atoms in an iron sulfide thin film are unevenly distributed on a substrate, strongly suggestive of the formation of an overall S-deficient film. The darkness of the iron rich area suggests that there is a lighter element such as carbon in this area of the film that tends to darken the contrast compared to the small crystallites observed which appear white.

The p-XRD patterns of the as-deposited films from complex (1) show hexagonal-phase iron sulfide $\left(\mathrm{Fe}_{0.975} \mathrm{~S}\right.$ ) (card number: 01-080-1032), dominating at the higher temperature of $450{ }^{\circ} \mathrm{C}$ (Fig. 6(a)). The reflection ( $h k l$ ) planes of (110), (201) (114) (214) and (220) corresponding to the $\mathrm{Fe}_{0.975} \mathrm{~S}$ phase were observed at $450{ }^{\circ} \mathrm{C}$. At the deposition temperatures of $350{ }^{\circ} \mathrm{C}$ and $400{ }^{\circ} \mathrm{C}$, the XRD patterns showed mixed phases of marcasite $\left(\mathrm{FeS}_{2}\right)$
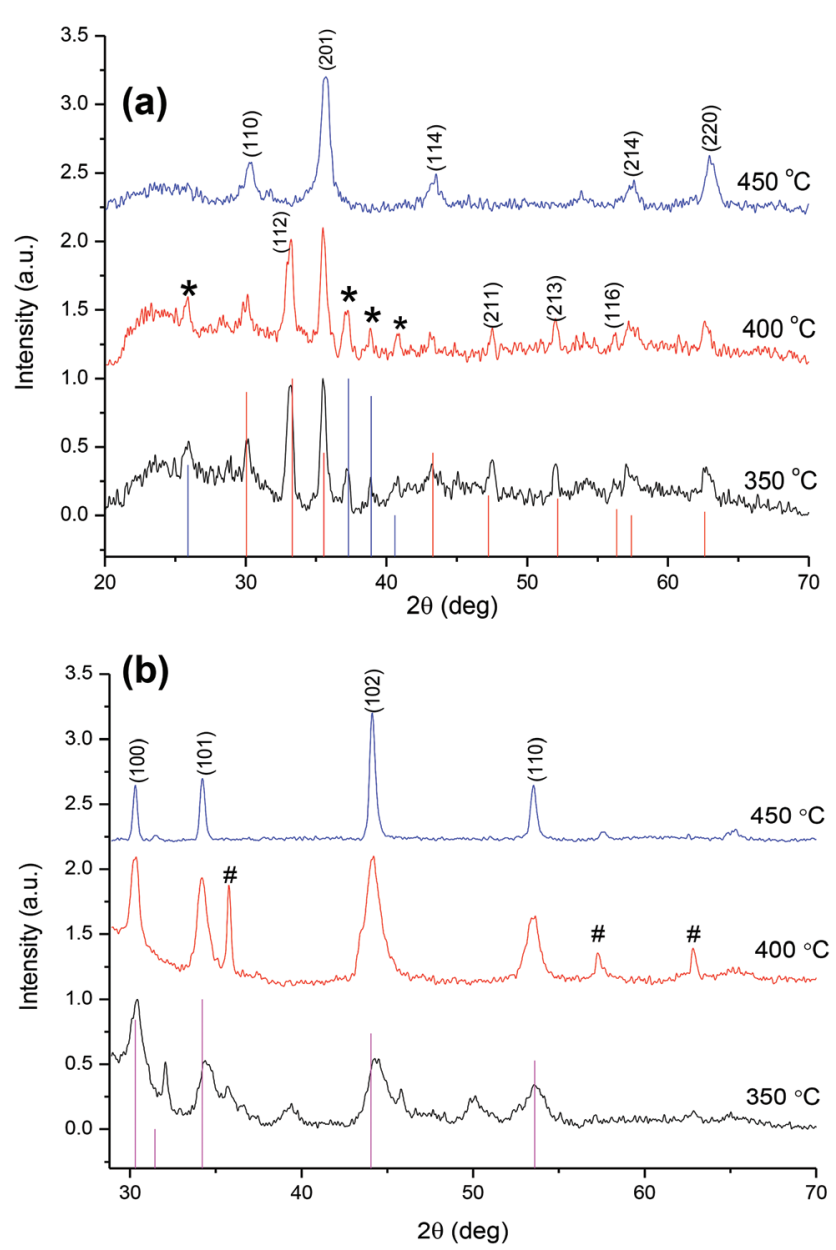

Fig. 6 (a) Powder XRD of iron sulfide ( $\mathrm{Fe}_{0.975} \mathrm{~S}$, red sticks) thin films deposited from toluene solutions of complex (1) at various temperatures. The asterisk symbol $(*)$ denotes the marcasite phase $\left(\mathrm{FeS}_{2}\right.$ represented by blue sticks). (b) Powder XRD of Fe-S thin films deposited from toluene solution of complex (2). (Purple sticks represent the standard pattern for hexagonal-pyrrhotite $1 \mathrm{~T}\left(\mathrm{Fe}_{0.95} \mathrm{~S}_{1.05}\right)$ phase). The symbol \# denotes the iron sulfide $\left(\mathrm{Fe}_{0.975} \mathrm{~S}\right)$ phase (card number: 01-080-1032). 
and iron sulfide $\left(\mathrm{Fe}_{0.975} \mathrm{~S}\right)$ phases. The reflections at 25.97\%, $37.38^{\circ}, 38.89^{\circ}$ and $40.59^{\circ}$ were indexed to the (110), (111), (120) and (200) planes of marcasite $\mathrm{FeS}_{2}$ (card number: 03-0652567). Mixed phases of marcasite $\left(\mathrm{FeS}_{2}\right)$ and hexagonal iron sulfide $\left(\mathrm{Fe}_{0.975} \mathrm{~S}\right)$ coexist at $350{ }^{\circ} \mathrm{C}$ and $400{ }^{\circ} \mathrm{C}$, while the latter are predominantly obtained in its pure phase at $450{ }^{\circ} \mathrm{C}$. The transformation of iron sulfide compounds into different phases is possible under certain conditions such as high temperature or pressure. ${ }^{30-32}$

A comparison of $\mathrm{p}$-XRD patterns for the iron sulfide film deposited from complex (2) by AACVD at 350, 400 and $450{ }^{\circ} \mathrm{C}$ is presented in Fig. 6(b). A pure hexagonal-pyrrhotite $1 \mathrm{~T}$ $\left(\mathrm{Fe}_{0.95} \mathrm{~S}_{1.05}\right)$ phase is formed at $450{ }^{\circ} \mathrm{C}$ (card number: 01-0750600), while at 350 and $400{ }^{\circ} \mathrm{C}$ some additional peaks are observed (denoted by the symbol \#) which matched a hexagonal iron sulfide phase $\left(\mathrm{Fe}_{0.975} \mathrm{~S}\right)$ (card number 01-080-1032). These results suggest that the mechanism by which the complexes decompose are different. Intergrowth involving different pyrrhotite types is known, ${ }^{33-35}$ and the degree of such intergrowths (micron to submicron) makes analysis difficult and therefore information on accurate $\mathrm{Fe}: \mathrm{S}$ ratios and the concentration of impurity is relatively incomplete for the pyrrhotite in this study. These results are similar to our recent reports, ${ }^{21,22}$ where formation of the pyrrhotite phase was observed at 400 and $450{ }^{\circ} \mathrm{C}$ when alkyldithiocarbamatoiron(III) complexes were used as single source precursors to deposit films by AACVD.

The UV-vis NIR absorption spectrum of the iron sulfide thin film deposited at 350, 400 and $450{ }^{\circ} \mathrm{C}$ is shown in Fig. 7. The as-deposited iron sulfide thin films absorb light in the visible and near-infrared spectral regions. Deposition from complex (1) at $350{ }^{\circ} \mathrm{C}$ displays a sharp absorption band gap of $1.63 \mathrm{eV}$, estimated from Tauc plots (inset, Fig. 7). ${ }^{36}$ The films deposited at 400 and $450{ }^{\circ} \mathrm{C}$ exhibited red shifted absorption properties $(\sim 1.25-1.34 \mathrm{eV})$ compared to those of $350{ }^{\circ} \mathrm{C}$. The blue shift observed for the absorption spectra may reveal the

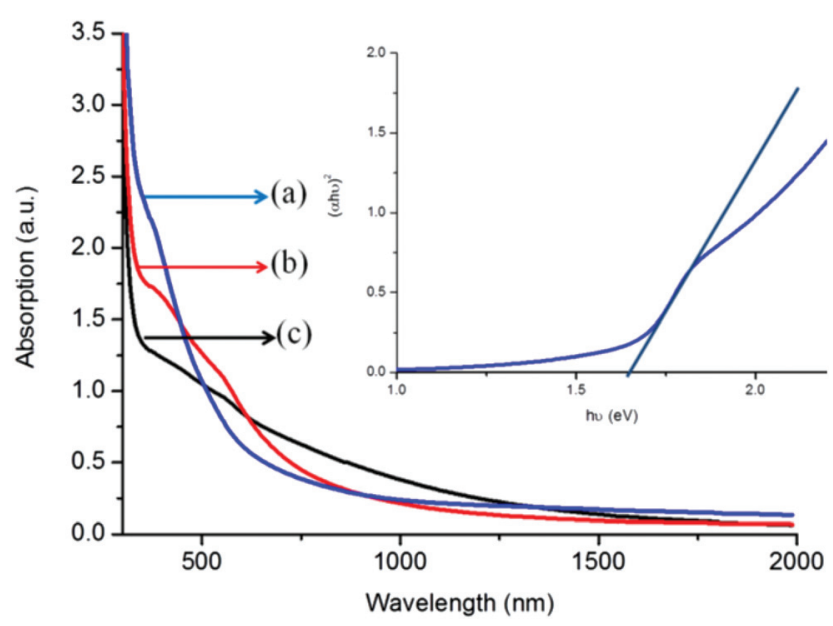

Fig. 7 UV-Vis-NIR absorption spectra of Fe-S thin films deposited at (a) 350, (b) 400 and (c) $450{ }^{\circ} \mathrm{C}$ from toluene solution of complex (1). Inset: a representative Tauc plot showing the estimated direct optical band gap of $\mathrm{Fe}-\mathrm{S}$ films deposited at $350^{\circ} \mathrm{C}$. formation of surface defects free ${ }^{37}$ and hence high optical performance activeness of the films in the visible and infrared region. The optical behaviour of the deposited films reveals that the absorption properties are temperature, size and structure dependent.

\section{Deposition of iron sulfide thin films from solution in chloroform}

The role of a solvent in the formation of thin films by AACVD can be significant and has been described on the physical basis of the enthalpy heat of combustion and vaporization, the nature of bonding between precursor and solvent molecules in aerosol droplets as well as the coordinating ability of the solvent, which in one way or another may influence the nucleation by changing the enthalpy of the system. ${ }^{38,39}$ Chloroform has a lower heat of combustion and vaporization (473.2 and $31.4 \mathrm{~kJ} \mathrm{~mol}^{-1}$, respectively), and thus evaporates faster, causing homogeneous nucleation. On the other hand, the higher heat of combustion and vaporization (3910.3 and $38.06 \mathrm{~kJ} \mathrm{~mol}^{-1}$, respectively) of toluene facilitates both homogeneous and heterogeneous nucleation growth of the particles. Indeed, the iron sulfide films deposited from chloroform aerosols were observed to be significantly different from those deposited from the toluene aerosols. The representative SEM images of iron sulfide thin films deposited at various temperatures are shown in Fig. 8. Irregular bundles of nanofiber struc-
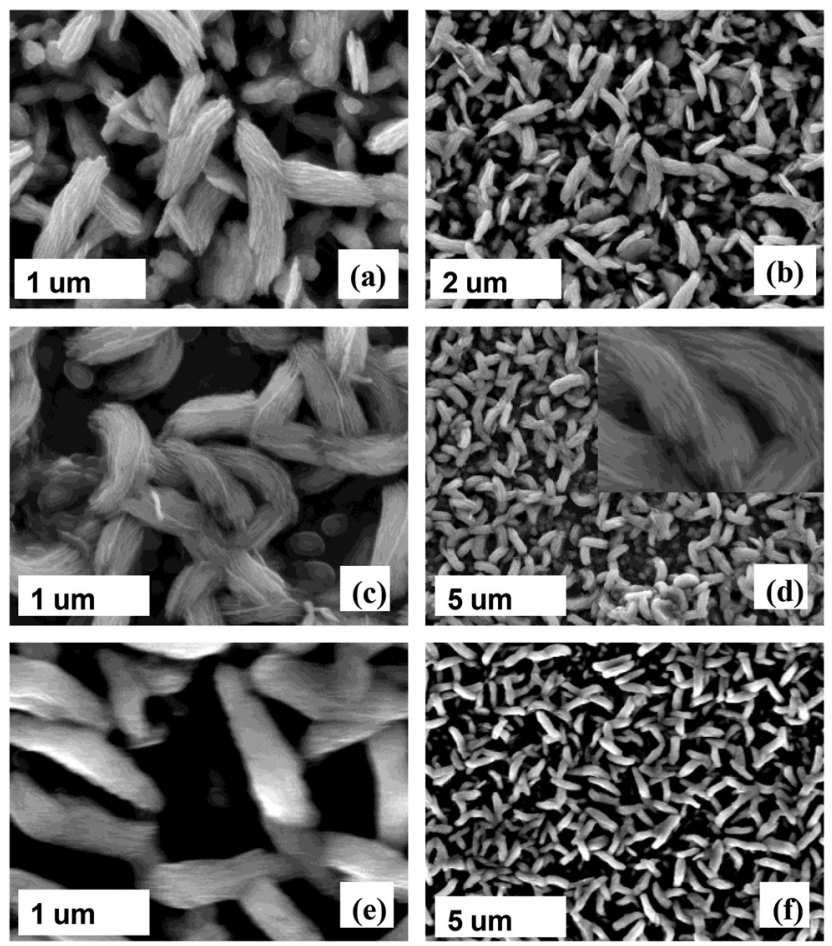

Fig. 8 Representative secondary electron SEM images of the iron sulfide thin films deposited at (a and b) $350{ }^{\circ} \mathrm{C}$ and $450{ }^{\circ} \mathrm{C}$ (c and d) for complex (1) and (e and f) $450^{\circ} \mathrm{C}$ using complex (2) using chloroform solvent. Inset: a zoomed-in high magnification image showing more structural features of the bundle of fibres. 
tures are observed when complex (1) was deposited at $350{ }^{\circ} \mathrm{C}$ with particle sizes ranging between 400 and $450 \mathrm{~nm}$. No significant morphological changes were observed when the temperature was increased (Fig. 8(c) and (d)). However, considerable increases in particle sizes to $530-580 \mathrm{~nm}$ and $600-650 \mathrm{~nm}$ are observed at 400 and $450{ }^{\circ} \mathrm{C}$, respectively. A similar morphological trend was observed for complex (2); Fig. 8(e) and (f) show a representative bundle of nanofiber-like structures obtained at $450{ }^{\circ} \mathrm{C}$ with sizes between 525 and $575 \mathrm{~nm}$.

The $\mathrm{p}$-XRD patterns of iron sulfide films grown from chloroform solutions of complex (1) at all temperatures (Fig. 9(a)) showed (112), (201), (203), (320), (220) and (222) reflections which correspond to hexagonal-phase iron sulfide $\left(\mathrm{Fe}_{0.975} \mathrm{~S}\right)$ (card number: 01-080-1032). Some minor peaks can be attributed to the smythite phase $\left(\mathrm{Fe}_{3} \mathrm{~S}_{4}\right)$ (card number 04-007-2189)
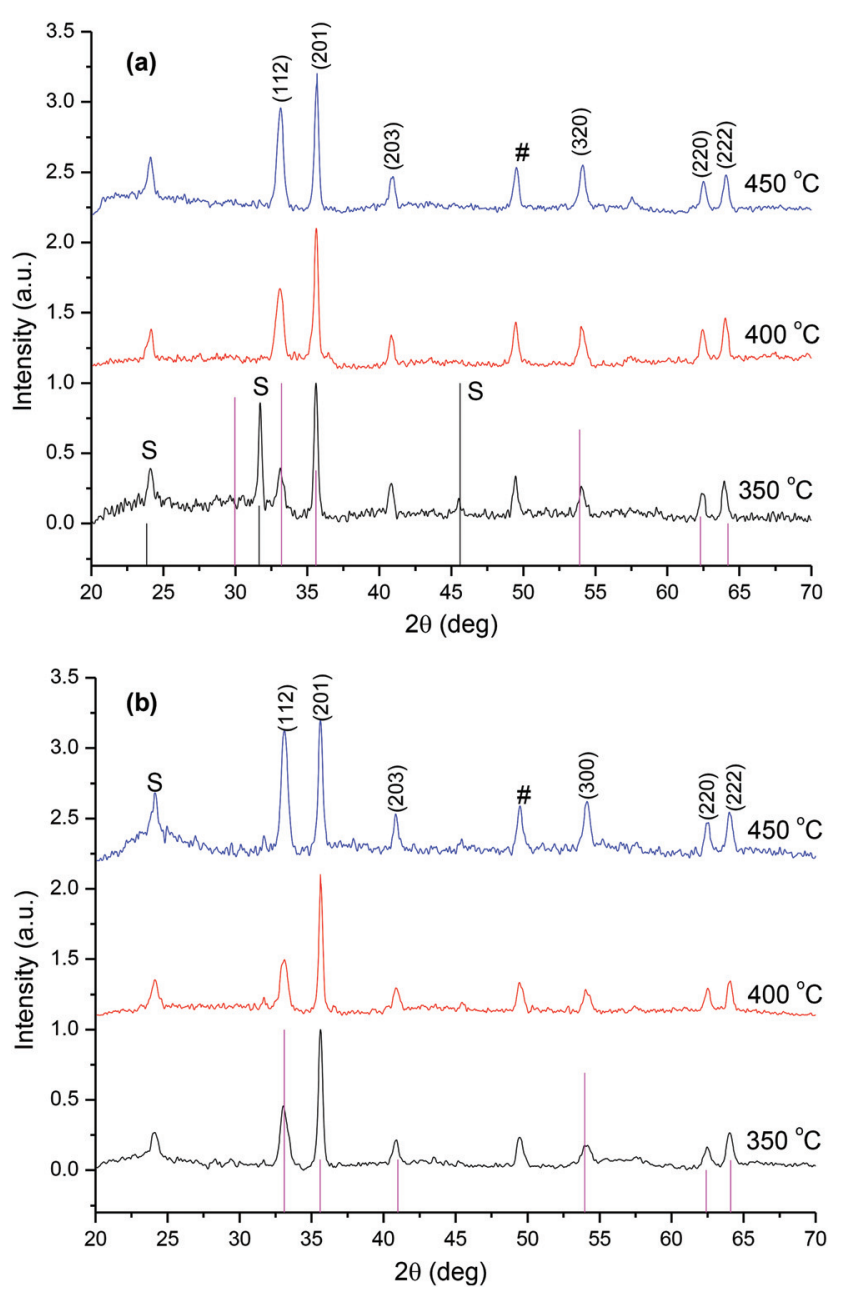

Fig. 9 (a) Powder XRD of Fe-S thin films deposited from complex (1) using chloroform as the solvent. (Purple and black sticks represent the standard card for the hexagonal phase $\left(\mathrm{Fe}_{0.975} \mathrm{~S}\right)$ and smythite $\left(\mathrm{S}=\mathrm{Fe}_{3} \mathrm{~S}_{4}\right)$ and \# = mackinawite (FeS)). (b) Powder XRD of Fe-S thin films deposited from complex (2) using chloroform as the solvent. (Purple sticks represent the standard pattern for the hexagonal phase $\left(\mathrm{Fe}_{0.975} \mathrm{~S}\right), \mathrm{S}=$ smythite $\left(\mathrm{Fe}_{3} \mathrm{~S}_{4}\right)$ and $\#$ = mackinawite $(\mathrm{FeS})$ ). are observed at $350{ }^{\circ} \mathrm{C}$, while a pure hexagonal phase is observed at temperatures $400{ }^{\circ} \mathrm{C}$ and $450{ }^{\circ} \mathrm{C}$. Furthermore, the intensity of the (112) reflection increases as a function of temperature. The growth of a hexagonal phase-iron sulfide $\left(\mathrm{Fe}_{0.975} \mathrm{~S}\right)$ from complex (2) dominates at all deposition temperatures (Fig. 9(b)). UV-Vis-NIR absorbance spectroscopy of a representative sample $\left(350{ }^{\circ} \mathrm{C}\right.$ for complex (1)) showed a broad absorption with the absorption maxima at around $1300 \mathrm{~nm}$ $(0.95 \mathrm{eV})$ at $350{ }^{\circ} \mathrm{C}$ (ESI Fig. $\left.3 \dagger\right)$, bathochromically shifted compared with films produced using toluene solvent. These results reveal that the solvent plays an important role in the reaction pathway.

\section{Effect of tert-butyl thiol ( $t$-BuSH)}

The composition and structure of $\mathrm{Fe}-\mathrm{S}$ films have been described in terms of $\mathrm{Fe}_{X} \mathrm{~S}_{Y}$ phases which are mainly temperature-dependent. ${ }^{30,31}$ There exist six sulfur atoms for each iron atom in compounds (1) and (2), seemingly sufficient to produce sulfur-rich phases such as pyrite. It is also known that higher temperature syntheses result in the formation of sulfurdeficient films. Therefore, an attempt was made to increase the sulfur content during the deposition experiments. A series of AACVD experiments were carried out by adding $1 \mathrm{~mL}$ $(8.87 \mathrm{mmol})$ of tert-butyl thiol $(t$-BuSH$)$. In this regard, toluene solutions of both complexes were used and depositions were conducted at 350,400 and $450^{\circ} \mathrm{C}$. High quality representative results for the deposition temperature of $450{ }^{\circ} \mathrm{C}$ are described.

Addition of $t$-BuSH to the precursor mix had a strong influence on the morphologies of the deposited iron sulfide films. SEM images (Fig. 10a and b) of iron sulfide films deposited using complex (1) at $450{ }^{\circ} \mathrm{C}$ showed the formation of flowerlike bundles of spherical-to-globular shaped crystallites with particle sizes ranging from 500 to $600 \mathrm{~nm}$. Complex (2) deposited double-layered films: the bottom one, a relatively

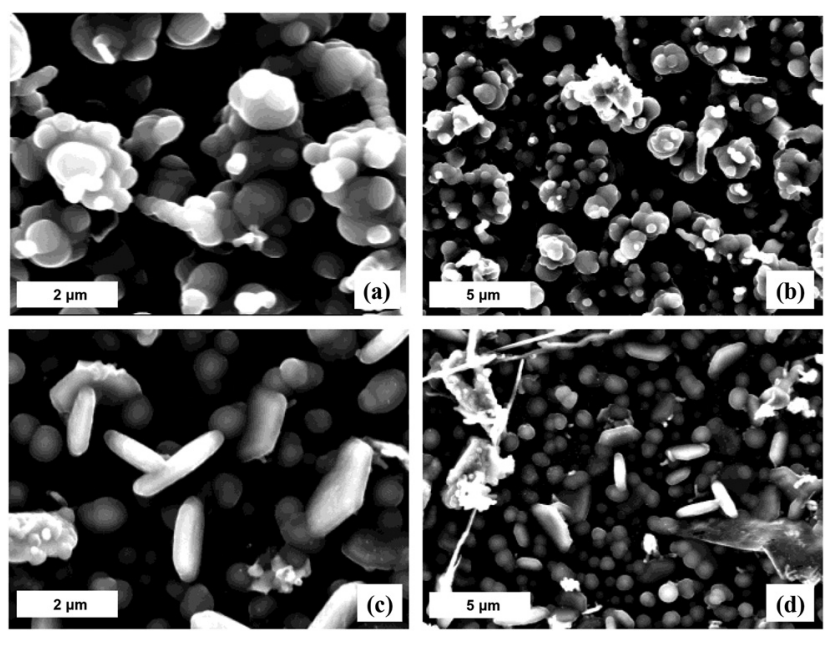

Fig. 10 SEM images of the iron sulfide thin films deposited at $450^{\circ} \mathrm{C}$ using ( $a$ and b) complex (1) and (c and d) complex (2). 
compact layer, is composed of spherical particles $(\sim 500 \mathrm{~nm})$, and a loose top layer is composed of mainly flake shaped crystallites $(900 \mathrm{~nm})$ (Fig. 10c and d). A significant increase in the sulfur content (S $53.8 \%$ and $\mathrm{Fe} 46.2 \%$ ) was observed as a result of using $t$-BuSH. The p-XRD patterns of deposited iron sulfide samples reveal two sharp reflections at $32^{\circ}$ and $45.8^{\circ}$ which we could not assign (ESI Fig. S4 $\dagger$ ).

Topological analysis of the films was performed using atomic force microscopy (AFM), and revealed the formation of uniform films (ESI Fig. S5 $\dagger$ ). The room temperature UV-Vis NIR absorption spectra, shown in ESI (Fig. S6 $\dagger$ ), of iron sulfide thin films deposited using complexes (1) and (2) both showed an absorption edge of approx. 1.7-2.0 eV, a hypsochromic shift compared with the reported values of iron sulfide. ${ }^{40,41}$ This blue shift phenomenon confirms the enrichment of the Fe-S film by sulfur, as a result of $t$-BuSH addition. It has been reported that sulfur vacancies and impurities are potentially responsible for lowering the band gap of iron sulfide particles. $^{37,42}$ Additionally, bulk sulfur vacancies are also responsible for nonconstant charge distribution, resulting in poor optical properties and photoconversion efficiency.

\section{Conclusions}

We have successfully synthesized tris-(piperidinedithiocarbamato)iron(III) (1) and tris-(tetrahydroquinolinedithiocarbamato)iron(III) (2) complexes and determined their X-ray crystal structures. Both complexes have been used as single source precursors for the deposition of iron sulfide thin films on glass substrates by the aerosol assisted chemical vapor deposition technique. Thermogravimetric and powder X-ray diffraction studies revealed the formation of iron sulfide(s). A mechanism for the decomposition of complex (1) was studied using thermogravimetric analysis, X-ray diffraction and gas chromatography mass spectroscopy. The mechanism showed that the decomposition of complex (1) proceeds through two steps; firstly detachment of one piperidinyl dithiocarbamato ligand, followed by complete removal of the remaining organic moiety. Different deposition parameters such as temperature and solvent were used and correlated with the morphological, structural and optical properties of the resultant deposited films. The morphology of the iron sulfide films has been found to be strongly dependent on the solvent and the amount of tert-butyl thiol added to the precursor mixture. X-ray diffraction studies revealed the formation of mixed phase and/or pure phase iron sulfide films, an effect which was found to be temperature dependent. Toluene and chloroform precursor solutions mainly formed the pyrrhotite and hexagonal phases of iron sulfide thin films at elevated temperatures. Optical measurements revealed the formation of blue shifted (0.95-2.0 eV) Fe-S films which were solely influenced by the structure and morphologies. The experimental conditions that we used allowed us to access iron sulfide in new ways by AACVD using dithiocarbamate precursors.

\section{Acknowledgements}

The authors are grateful to the National Research Foundation (NRF), South Africa, Royal Society Leverhulme Africa Award and Royal Society DFID Africa Capacity Building Initiative for financial support. The author also acknowledges the University of Zululand Research Office for financial support and the POB group of the University of Manchester for facilitating this research.

\section{Notes and references}

1 P. A. Janick and L. M. Siegel, Biochemistry, 1982, 21, 3538.

2 W. O. Gillum, L. E. Mortenson, J. S. Chen and R. H. Holm, J. Am. Chem. Soc., 1977, 99, 584.

3 C. Di Giovanni, W.-A. Wang, S. Nowak, J.-M. Grenèche, H. Lecoq, L. Mouton, M. Giraud and C. Tard, ACS Catal., $2014,4,681$.

4 D. Kong, J. J. Cha, H. Wang, H. R. Lee and Y. Cui, Energy Environ. Sci., 2013, 6, 3553.

5 E.-J. Kim, J.-H. Kim, A.-M. Azad and Y.-S. Chang, ACS Appl. Mater. Interfaces, 2011, 3, 1457.

6 G. L. Henriksen and D. R. Vissers, J. Power Sources, 1994, 51, 115.

7 H. Geng, L. Zhu, W. Li, H. Liu, L. Quan, F. Xi and X. Su, J. Power Sources, 2015, 281, 204.

8 H. Chen, L. Zhu, H. Liu and W. Li, J. Power Sources, 2014, 245, 406.

9 H. Wang and I. Salveson, Phase Transform., 2005, 78, 547.

10 S. A. Kissin and S. D. Scott, Econ. Geol., 1982, 77, 1739.

11 D. J. Vaughan and J. R. Craig, Minerals Chemistry of Metal Sulfides, Cambridge University Press, Cambridge, 1978.

12 X. F. Qian, X. M. Zhang, C. Wang, Y. Xie, W. Z. Wang and Y. T. Qian, Mater. Sci. Eng., 1999, 64, 170.

13 D. Hobbs and J. Hafner, J. Phys.: Condens. Matter, 1999, 11, 8197.

14 S. Shukla, N. H. Loc, P. P. Boix, T. M. Koh, R. R. Prabhakar, H. K. Mulmudi, J. Zhang, S. Chen, C. Fan Ng, C. H. A. Huan, N. Mathews, T. Sritharan and Q. Xiong, ACS Nano, 2014, 8, 10597.

15 J. Xia, J. Jiao, B. Dai, W. Qiu, S. He, W. Qiu, P. Shen and L. Chen, RSC Adv., 2013, 3, 6132.

16 L. Li, M. Cabán-Acevedo, S. N. Girard and S. Jin, Nanoscale, 2014, 6, 2112.

17 D. Liang, M. Cabán-Acevedo, N. S. Kaiser and S. Jin, Nano Lett., 2014, 14, 6754.

18 R. Morrish, R. Silverstein and C. A. Wolden, J. Am. Chem. Soc., 2012, 134, 17854.

19 V. G. Bessergenev, R. J. F. Pereira and A. M. B. do Rego, Surf. Coat. Technol., 2007, 201, 9141.

20 M. J. Almond, H. Redman and D. A. Rice, J. Mater. Chem., 2000, 10, 2842.

21 M. Akhtar, A. L. Abdelhady, M. A. Malik and P. O’Brien, J. Cryst. Growth, 2012, 346, 106. 
22 S. Khalid, E. Ahmed, M. A. Malik, D. J. Lewis, S. A. Bakar, Y. Khan and P. O'Brien, New J. Chem., 2015, 39, 1013.

23 S. Saeed, R. Hussain and R. J. Butcher, J. Coord. Chem., 2014, 67, 1693.

24 P. O’Brien, D. J. Otway and J.-H. Park, Mat. Res. Soc. Symp. Proc., 2000, 606, 133.

25 S. D. Disale and S. S. Garje, Appl. Organomet. Chem., 2010, 24, 734 .

26 K. Ramasamy, M. A. Malik, M. Helliwell, F. Tuna and P. O’Brien, Inorg. Chem., 2010, 49, 8495.

27 G. M. Sheldrick, A short history of SHELX, Acta Crystallogr., Sect. A: Found. Crystallogr, International Union of Crystallography, 2008, 64, 112.

28 L. D. Nyamen, V. S. R. Pullabhotla, A. A. Nejo, P. Ndifon and N. Revaprasadu, New J. Chem., 2011, 35, 1133.

29 M. Akhtar, J. Akhter, M. A. Malik, P. O’Brien, F. Tuna, J. Raftery and M. Helliwell, J. Mater. Chem., 2011, 21, 9737.

30 O. Kubaschewski, "Iron-Sulfur", Iron-Binary Phase Diagrams, Springer-Verlag, Berlin, 1982, p. 125.

31 D. J. Vaughan and A. R. Lennie, Scientific Progress (Edinburgh), 1991, 75, 371.

32 R. A. Berner, Science, 1962, 137, 669.
33 C. A. Francis and J. R. Craig, Am. Mineral., 1976, 61, 21.

34 D. F. Shriver, P. W. Atkins, T. L. Overton, J. P. Rourke, M. T. Weller and F. A. Armstrong, Inorganic Chemistry, W. H. Freeman, New York, USA, 2006.

35 W. W. Barker and T. C. Parks, Geochim. Cosmochim. Acta, 1986, 50, 2185.

36 J. Tauc, Optical Properties of Solids, Academic Press, New York, USA, 1966.

37 M. Cabán-Acevedo, N. S. Kaiser, C. R. English, D. Ling, B. J. Thompson, H.-E. Chen, K. J. Czech, J. C. Wright, R. J. Hamers and S. Jin, J. Am. Chem. Soc., 2014, 136, 17163.

38 A. A. Tahir and K. G. U. Wijayantha, J. Photochem. Photobiol., A, 2010, 216, 119.

39 C. Piccirillo, R. Binions and I. P. Parkin, Chem. Vap. Deposition, 2007, 13, 145.

40 J. P. Wilcoxon, P. P. Newcomer and G. A. Samara, Solid State Commun., 1996, 98, 581.

41 A. M. Karguppikar and A. G. Vedeshwar, Phys. Status Solidi A, 1988, 109, 549.

42 C. Wadia, Y. Wu, S. Gul, S. K. Volkman, J. Guo and A. P. Alivisatos, Chem. Mater., 2009, 21, 2568. 